\title{
Seducir o adoctrinar. La educación ante las formas moderna y posmoderna de la esclavitud
}

\author{
Seduce or indoctrinate. Education in the face of modern and postmodern \\ forms of slavery
}

Seduzir ou doutrinar. Educação diante das formas modernas e pós-modernas de escravidão

William Roberto Darós
${ }^{1}$
https://orcid.org/0000-0002-8475-3514
Plata - Libertador, Entre Ríos, Argentina

Recepción: 15/08/2019

Evaluación: 27/02/2020

Aceptación: 01/04/2020

Artículo de Investigación - Reflexión

https://doi.org/10.19053/01227238.11352

\section{RESUMEN}

El objeto de este trabajo se G., P. Sibilia, O. Reboul. La estrategia de describen dos formas de dominación: el adoctrinamiento y la seducción, con el objetivo de hacer ver su actual vigencia. En este contexto, se aporta el advertir como la población es mayoritariamente seducida e impone las condiciones. El método es el propio de los ensayos filosóficos y la reflexión sobre los acontecimiento de actualidad. Se utilizan las fuentes de los sociólogos y filósofos de mayor prestigio actual como lo son G. Lipovetzsky y Z. Bauman, análisis utilizada es la que pone de manifiesto y critica, con originalidad el mecanismo de seducción: el seducido está en la condición de necesidad, primero y, después, de placenteramente esclavizado, por lo que no advertirá la dominación que se ejerce sobre él, perdiéndose sutilmente la libertad humana. La adicción a la propia imagen (selfish) y al celular o teléfono móvil es un claro ejemplo, que los adictos difícilmente querrán admitir. En conclusión se ponen de

1 Licenciado y doctorado en Filosofía, es docente de filosofía, e investigador principal, -con sede en la Universidad del Centro Educativo Latinoamericano (UCEL)-, del Consejo Nacional de Investigaciones Científicas y Técnicas (CONICET), correo electrónico: daroswr@yahoo.es 
manifiesto las estrategias narcisistas de supervivencia: retirarse en el presente, reciclando la juventud. El narcisismo neutraliza el universo social, vaciando las instituciones de sus inversiones emocionales y el yo se vacía de su identidad, por eso requiere constantemente de las selfishes para reírse de sí mismo. El yo pierde su referencia de unidad por exceso de información insustantiva.

Palabras clave: educación; adoctrinamiento; seducción; modernidad; posmodernidad.

\section{ABSTRACT}

In this brief essay there is matter of describing two enslavement ways, we should be attentive in the education process. The enslavement of the ideas and lifestyles of modernity until the end of the 20th century imposed rigid, socialized and revolutionary ways of social coexistence, liberalism first and socialism later. Postmodernism has currently psychologized lifestyles and it enslaves by seducing. Seduction by being selfish is not a violent process, but a pleasant one and it always seems to leave us a margin of freedom; for this reason it turns out to be a socially and morally perhaps more dangerous process, since it tries to enslave without the crowds noticing it; even more so that one can feel satisfied.

Key words: education; indoctrination; seduction; modernity; postmodernity.

\section{RESUMO}

Este breve ensaio trata de descrever formas de escravidão das que se deve estar atento no processo de educação. A escravidão das ideias e formas de vida da modernidade até fins do século XX impuseram formas rígidas, socializadas e revolucionárias de convivência social: liberalismo primeiro e socialismo depois. Atualmente, pós-modernidade psicologizou as formas de vida e escraviza seduzindo. A sedução, o selfish, não é um processo violento, mas agradável e parece deixar-nos sempre uma margem de liberdade; por esse motivo é um processo socialmente e moralmente, talvez, mais perigoso, pois objetiva escravizar sem que a multidão o advirta; ainda mais para que se sintam satisfeitos.

Palavras-chave: educação; doutrinação; sedução; modernidade; pós-modernidade.

\section{INTRODUCCIÓN}

En una época en la que Latinoamérica ha asumido el compromiso de educar desde el valor central de la solidaridad, el respeto y la tolerancia, los educadores deberían tener presente la transformación que se está produciendo en el proceso de sometimiento de las personas. En el siglo XX, en particular, se utilizó el proceso de adoctrinamiento -o también llamado de ideologización - para someter a las personas a las formas de pensar de un régimen político, religioso o social autoritario. Se trata de una forma de proceder fuerte, impuesta, social y mayoritaria.

A fines de ese siglo, y actualmente, se prefiere utilizar el proceso de seducción. Este proceso no es violento sino placentero y parece dejarnos siempre un margen de libertad; por ello resulta ser un proceso social y moralmente quizás 
más peligroso, puesto que intenta esclavizarnos sin que consigamos advertirlo, es más, haciéndonos sentir satisfechos.

La seducción ${ }^{2}$ - como etimológicamente lo indica el término mismo se- $d u$ cere, refiere a conducirse - tiene acepciones: 1) entendida como autoconducción o seducción: el ser humano estima que él se está conduciendo a sí mismo y siente placer en ello; 2) entendida como conducir a otro, como lo indica la primera acepción del diccionario, implica el "engañar con arte y maña; persuadir suavemente para algo malo"; pero, además, atraer, cautivar el ánimo de los otros en beneficio propio.

El objeto, persona o acontecimiento que seduce nos mueve desde afuera y nos conmueve desde dentro: en la seducción somos cómplices. En última instancia, lo que nos mueve es la necesidad de afecto (donde caben otras necesidades como las sexuales, las de satisfacción del ego, de ser admirado, comprendido, apreciado, contenido, de abrazar y ser abrazado, etcétera), la cobertura de un profundo vacío existencial; pero siempre queda en claro que es lo que nos seduce lo que impone las condiciones. El seducido está en la condición de necesidad, primero, y de esclavizado, después.

Lo delicado del proceso de seducción para el seducido se halla en que la seducción no se presenta como riesgosa ni violenta, sino como atractiva desde el interior mismo del seducido, como un cosquilleo casi irresistible, y mayores sin consecuencias sociales. Por el contrario, el estado psicológico del miedo hace referencia a sentimientos angustiantes (paralizantes o de fuga) que experimenta una persona o grupo ante situaciones que considera una amenaza o riesgo y que pueden ser creadas o exacerbadas por sectores que se encuentran con el poder ${ }^{3}$.

Nadie vería como peligroso el hecho de que alguien se conduzca a sí mismo; pero lo peligroso de este hecho es que la seducción hace engañoso ese hecho de la autoconducción. En el proceso de seducción, el placer que la acción produce puede hacer que se omita hacer lo que es justo y no solamente lo placentero. El placer no está reñido con la moral, siempre que no se oponga a la justicia.

Una de las ideas más seductoras - y generadoras de adicción, social y mayoritariamente muy aceptada - de la modernidad ha sido la idea de ser libre; pero no todo acto es libre si ese acto es generado y arrastrado a hacer lo injusto por el placer que lo seduce. El placer desenfrenado del avaro, seducido por el deseo de poseer sin límites, no es generador de una buena vida con calidad humana, deseable en todos. El uso moral de la libertad, para ser bueno, debe ser además justo y no guiado arbitrariamente por el placer de quien lo realiza (y, con eso, se daña a sí mismo o a otros).

2 Según el Diccionario de la lengua española, el verbo transitivo "seducir" (Del lat. seducère) significa: 1. Persuadir a alguien con argucias o halagos para algo, frecuentemente malo. 2. Atraer físicamente a alguien con el propósito de obtener de él una relación sexual. 3. Embargar o cautivar el ánimo.

Cfr. Ambrosio Javier Luna Reyes, "Ilusión, seducción, persuasión", Tópicos del Seminario n. ${ }^{\circ} 14$ (2005); César Ojeda Figueroa, La presencia de lo ausente. Ensayo sobre el deseo (Santiago de Chile: Cuatro Vientos Editorial, 2018).

3 María del Carmen Aray, "El miedo asecha y el consumo seduce. Dos caras del modelo psicológico dominante en tiempos de globalización”, Universitas Humanística n. ${ }^{\circ} 67$ (2009): 55. 
En la posmodernidad, esta idea se ha transformado en un déjate libremente llevar. Como veremos, se dan adicciones socialmente aceptables y otras no aceptables por las mayorías. Las adicciones - que, en cuanto seducen, siempre quitan un margen de libertad - cuando son socialmente aceptadas, son doblemente más peligrosas, pues no solo seducen sino, además, parecen ser positivas (generadores de una mayor calidad de vida placentera), se hacen socialmente aceptables y resultan ser armas ideológicamente masivas.

\section{La ideología}

Frecuentemente se mal entiende este concepto tomándolo como sinónimo de "una neutra manera de pensar", o como una filosofía. Mas quien tiene una filosofía no tiene necesariamente una ideología, si no la impone e intenta dominar con ella.

El concepto de ideología, inicialmente, significó el estudio de las ideas, pero luego pasó a representar, sobre todo con Karl Marx, un proceso complejo de dominación (económica, religiosa, cultural, etcétera) de mayorías por parte de minorías. Las ideologías suelen constar de dos componentes: una representación del sistema, y un programa de acción para imponer ese sistema de ideas. El primer componente proporciona un punto de vista propio y particular sobre la realidad, vista desde un determinado ángulo - creencias, preconceptos o bases intelectuales-, a partir del cual se analiza y enjuicia, habitualmente comparándolo con un sistema alternativo, real o ideal. El segundo componente tiene como objetivo acercar en lo posible el sistema real existente al sistema ideal pretendido, mediante la utilización oculta o más o menos implícita de medios para imponer las ideas con las que se pretende justificar esa imposición como lo mejor para todos, pero que encubre el beneficio de unos pocos.

Para Karl Marx, el proceso ideológico capitalista impone un estilo de vida y de cultura fundado en la producción económica. El conjunto de las relaciones de producción forma la estructura económica de la sociedad, la base real sobre la que se levanta la superestructura jurídica y política y a la que corresponden determinadas formas de conciencia social. El modo de producción de la vida material condiciona el proceso de la vida social política y espiritual en general. No es la conciencia del hombre la que determina su ser sino, por el contrario, el ser social es lo que determina su conciencia. Si se dice, por ejemplo: "la libre oferta y la libre demanda es lo mejor para todos", y no parece existir nada objetable en esto; pero no se advierte que esto es válido si existen libertad y medios para demandar y comprar. Mas cuando se tienen necesidades básicas insatisfechas, y no se tiene con qué comprar (por falta de trabajo, o salarios adecuados), "la libre demanda" (ir a comprar a quien ofrece el precio más favorable al comprador) son palabras vacías, que cubren el hecho de que quien tiene abundancia de bienes para vender, puede esperar y salir siempre ganando. "La libre oferta y la libre demanda" no es entonces lo mejor para ambas partes, sino un engaño que cubre el beneficio del más fuerte económicamente. Desde un punto de vista 
religioso, un inquisidor podía justificar ideológicamente su proceder afirmando que era mejor quemar el cuerpo de la bruja, pero posibilitar que salve su alma (cuando un sacerdote le presentaba un crucifijo para que lo besara mientras lo quemaban en la hoguera), o para que no dañe a los demás con su herejía; pero, en realidad, el beneficio del proceso inquisitorial era siempre para el inquisidor que se quedaba con sus bienes materiales para pagar el proceso y mantener o aumentar su poder atemorizando a las multitudes con la pena de la hoguera si no se procedía en forma acorde a la verdad poseída por el inquisidor.

En la modernidad del siglo XX, la ideología se vio en el vehículo de grandes movimientos sociales y de pensamiento, sobre el soporte de grandes masas que fueron adoctrinadas por los nuevos medios de comunicación y la propaganda, cuando la violencia y la represión fueron insuficientes.

En el siglo XXI, con la Posmodernidad, la forma de imponer el dominio se ha hecho mucho más sutil y difícil de percibir: la imposición de los más fuertes sobre los más débiles se realiza mediante la seducción, mediante la generación del placer reforzado por el uso masivo de la tecnología. En la Modernidad, fácilmente se lograba que una mayoría percibiera, con indignación, las diferencias entre pocos ricos muy ricos y muchos pobres crecientemente más pobres. En la Posmodernidad se diluye esa percepción, encolumnadas todas las personas tras la seducción placentera del consumo masivo que ofrece la mentalidad de capitalización, acumulación, uso y abuso de bienes. Como afirmaba Zygmunt Bauman, el capitalismo se basa en esto: "en deshacernos de lo que tenemos, aunque funcione perfectamente, para demostrar a los que nos rodean que tenemos el último modelo. Así es que tenemos capitalismo para rato" ${ }^{4}$.

\section{Adoctrinamiento}

Cuando se acentúa el poder de imposición de una manera de pensar y actuar, la ideología suele ser llamada adoctrinamiento. Una doctrina no es una filosofía ni una manera cualquiera de pensar o creer. Con doctrina significamos un conocimiento que, si bien pudo haber sido discutible y discutido, ya no se discute más: ahora se lo acepta o no se lo acepta. Si alguien acepta los conocimientos y formas de obrar antes discutibles y discutidas, ahora pertenece al grupo (religioso, económico, social) de los creyentes que estiman, en el mejor de los casos, poseer la verdadera creencia, ser los mejores del grupo social.

Por adoctrinamiento (a veces también llamado proceso ideologizador) se entiende aquí un mecanismo teórico-práctico de asumir una doctrina, cuyo punto más alto es el lavado de cerebro de la persona que es sometida a él. Las ideologías pueden tener distinto signo político (tanto de derecha como de izquierda) o religioso o cultural; pueden ser violentas o aparentemente pacíficas, pero funcionan de la misma manera.

4 Zygmunt Bauman, entrevista por Vis Molina, 12 de marzo de 2013, El Cultural. https://elcultural.com/Zygmunt-Bauman 
El hecho es que este proceso puede hacerse presente, con frecuencia, en el aula. Por ello, analicemos algunos de sus supuestos y fases:

a) El adoctrinamiento es posible si se suprime - sin que la víctima lo advierta, seduciendo-, la libertad en el pensar. Por esto, las ideologías son una falsa conciencia que hace pasar por verdadero lo que es la conveniencia del victimario, del dominador.

b) El adoctrinamiento debe conseguir que la víctima piense que la verdad es una sola y de una sola forma: la del ideologizador, transformando los diversos modos de pensar en un único modo (lógico y psicológico) de pensar: el del ideologizador.

c) El adoctrinamiento trata de aislar, psicológica o socialmente, a la víctima, desacreditando otros criterios de juicios o modos de pensar que difieren del suyo. Suprime de esta manera formas de confrontación, de pro y contra, respecto de los puntos de vista del ideologizador.

d) El adoctrinador culpabiliza a la víctima, como enemiga de la verdad, de sus creencias, de la patria o de otros valores, si la víctima se resiste a pensar como él. Dado que el ideologizador concibe la verdad como única y de una única forma, toda divergencia con su forma es considerada una falta contra la verdad sin más, no contra el ideologizador.

e) Pero a quien obra dentro de la ideología (y piensa y actúa como el ideologizador) es liberado de toda culpa, porque la ideología le asegura, al obrar, la verdad y la justicia de su parte.

f) La aceptación de la ideología que trata de imponérsele a una víctima comienza con la abdicación de los propios modos (lógicos y psicológicos) de pensar, de su libertad para la crítica en el pensar desde fuera del sistema de explicación que se le ofrece. El que se opone al proceso ideologizador es capaz de pensar y obrar negando (no aceptando) lo que se le impone como verdadero y justo.

g) La aceptación del punto de vista del adoctrinador supone, luego, optar por su opción, ver con sus ojos, juzgar con su mente; implica, diría Kant, volver a la minoría de edad.

h) Aceptada la concepción ideológica del adoctrinador que se le presenta a la víctima, esta hace una relectura de los hechos y teorías desde la perspectiva de la ideología, calificándola como verdadera, y falsas las otras lecturas.

i) La ideología es, entonces, un falso conocimiento. Puede pretender ser científico, aportar gran cantidad de argumentos; pero se trata de un sistema cerrado a una crítica externa a sus principios o puntos de vista, los que deben asumirse sin crítica.

j) Mas el proceder adoctrinante, ideologizador, es inmoral, ya sea porque en nombre de la verdad suprime la libertad del hombre; ya sea porque no

5 Cfr. Olivier Reboul, L'endoctrinement (París: PUF, 2007), 37. William Daros, Epistemología y didáctica (Rosario: Mathesis, 1984), 115; José Ramón García, "Teoría crítica en Ciencias Sociales: Conocimiento, racionalidad e ideología", Revista de Ciencias Sociales n. ${ }^{\circ} 80$ (1998) 
teme presentar lo falso como verdadero. Esta actitud puede encarnarse en un hombre particular o en un grupo sociopolítico. Los docentes saben que todo ente tiende a permanecer en su ser y a desarrollarlo, a no ser que una causa externa lo suprima o limite. En consecuencia, toda persona o grupo con poder tiende a permanecer en el poder y crecer si le es posible. Por ello, todo poder de derecha, de izquierda o de centro, tenderá a permanecer en su posición y, si le es posible, a crecer; pero cuando se pierde el sentido ético del poder, este se absolutiza, e intentará permanecer en el poder y aumentarlo con todos los medios, lícitos e ilícitos, sin importarle presentar lo falso como verdadero; sin importarle suprimir o imponer la verdad con un acto arbitrario; sin importarle, si le conviene, suprimir la libertad en nombre de la verdad o la verdad en nombre de la libertad ${ }^{6}$, sometiendo en última instancia a las dos a mi decisión.

k) Mas por otra parte, la tolerancia de una persona o de un grupo de personas, en el uso de la libertad, para quien no piensa como esa persona o grupo, puede tener un límite: el límite de la mutua tolerancia para buscar cómo son las cosas (la verdad de las cosas o acontecimientos). No se puede tolerar, en nombre de la tolerancia, a los intolerantes; porque ser intolerante no es moral y lo inmoral de hecho no da derecho. El derecho, en efecto, es la capacidad para poder realizar un acto, que no puede ser impedido por otro, precisamente porque es lícito, justo, no me daña ni daña a un tercero. En caso de conflictos habrá que jerarquizar los deberes y derechos, y los derechos entre sí. El uso de la fuerza se justifica solo para proteger la realización de un acto justo. Ahora bien, la raíz de la justicia se halla en el (libre) reconocimiento de la verdad. Por lo tanto, quien no la reconoce, y me impide a mí reconocerla, se convierte en un intolerante, ante el cual tengo derecho a la defensa. Tanto alumnos como docentes tienen ese derecho ante un proceso ideologizador.

Como veremos, la mejor herramienta contra el intento de adoctrinar o ideologizar, tanto de un docente, como de otros medios informales de enseñanza y de aprendizaje de conductas sociales, se halla en un ámbito de libertad donde se pueda ejercitar la crítica, esto es, en el uso de criterios o medidas diversas, de modo que se hagan patentes las intenciones ocultas de quienes pretenden poseer la verdad, pero no someterla públicamente a discusión, como sucede cuando el docente presenta sus conocimientos como si fuesen - sin más - verdaderos o se mofa de las opiniones ajenas.

La actitud dogmática es esclavizante; implica cerrar toda puerta a la discusión; supone clausurar la posibilidad de expresar opiniones. Esta actitud constituye un riesgo real cuando, en el proceso de enseñar, los docentes no solo ponen en consideración los conocimientos, estimados verdaderos; sino que, además, los imponen como tales. La verdad no se impone: se propone, se muestra o demuestra; pero, después de esto, aún permanece libre la voluntad del que aprende y que

6 Cfr. Hugo Quiroga, Susana Villavicencio y Patrice Vermeren, comps., Filosofías de la ciudadanía. Sujeto político y democracia (Rosario: Homo Sapiens Ediciones, 1999); Octavio Ianni, La sociedad global (México: Siglo XXI, 2008). 
debe aceptar esos conocimientos libremente como verdaderos, si no desea autoengañarse.

Indudablemente que quien no acepta algo verdadero como verdadero, se engaña y se daña moralmente porque se miente. Pero aun en este caso, la presencia de la verdad no da derecho a suprimir la libertad de nadie, mientras no se convierta en un intolerante de mi derecho a la verdad, a saber cómo son las cosas. La libertad es el valor supremo subjetivo de una persona; pero este valor vale porque la persona acepta la verdad y ese valor se convierte en verdadera libertad: la libertad de una persona, que libremente se opone a la verdad (al conocimiento de cómo son las cosas y acontecimientos), se degrada moralmente ella misma. Por ello, el valor supremo objetivo de la persona se halla en lo verdadero: en buscar libremente saber cómo son las cosas, sea que esto me beneficie o me dañe subjetivamente. El ser objetivo dignifica (da valor no arbitrario) al sujeto que lo reconoce.

¿Pero acaso la verdad no es una sola, como suele decirse? Sostener que la verdad es una sola es una simplificación que lleva a un error ${ }^{7}$. Debemos tener presente que lo que llamamos verdad se da en el intelecto humano. La verdad no es una cosa extramental ni es la mente que la advierte.

La verdad es un sustantivo abstracto que hemos construido a partir de algunos conocimientos que son verdaderos, esto es, de un conocimiento en el que se advierte que la inteligibilidad de un ente coincide con ese ente.

Utilizaremos aquí referencias de Tomás de Aquino para sostener, como él lo hacía, que hay diversidad de la verdad humana sin que esto implique un relativismo. No es suficiente conocer un ente para saber si es verdadero; es necesario, además, advertir la adecuación o conformidad del ente con su inteligibilidad ${ }^{8}$. Hay, pues, tres elementos que intervienen para que un conocimiento sea verdadero: $1 .^{\circ}$ ) el ente (con su forma real o extramental); $\left.2 .^{\circ}\right)$ la inteligibilidad del ente (con su idea o forma inteligible o intramental); 3. ${ }^{\circ}$ ) el intelecto en el cual el hombre advierte la adecuación o igualdad de las dos formas anteriores. Cuando el hombre advierte esta característica de la conformidad o adecuación (que se da en el intelecto) entre lo inteligible del ente y el ente, entonces advierte que el conocimiento que observa es verdadero9. Allí se ha dado lo que llamamos "verdad".

La verdad se logra mediando un proceso de abstracción, esto es, de considerar separadamente lo sensible de lo inteligible de un ente. Esta primera abstracción no debe confundirse con otras abstracciones en las que se considera separadamente, por ejemplo, el género respecto de la especie, el accidente respecto de la sustancia, etcétera.

Al iniciar el proceso de conocer se da una primera abstracción (llamada también "iluminación") que abarca toda la cosa: todo lo sensible está ahora

$7 \quad$ Cfr. William R. Daros, "Diversidad de la verdad y relativismo en el pensamiento de Tomás de Aquino" (Estratto da Atti dell'VIII Congresso Tomistico Internazionale, Napoli, vol. V, 1982), 222-246.

8 "Ens intellectum est verum: non tamen intelligendo ens, intefligitur verum" (ibíd.). "Ventas est adaequatio rei et intellectus". Santo Tomás de Aquino, Suma de Teología, I, q. 16, a. 1 (Madrid: Biblioteca de Autores Cristianos, 1998).

9 Cfr. Suma de Teología (S. Th.), I, q. 16, a. 2. 
en lo inteligible o idea, si bien está en un mundo diverso (como inteligido, desmaterializado, desensibilizado, espiritualizado). En las otras abstracciones siempre encuentra considerada solo una parte de lo que es la cosa entendida.

Según Tomás de Aquino, en efecto, nada impide al intelecto humano conocer algo particular en cuanto es particular o individualizado. Lo que no puede el intelecto es conocer lo particular sensible en cuanto sensible. Al conocer, las condiciones sensibles o sentidas que individualizan al ser inteligido son dejadas de lado (abstraídas) y se considera a un ente en cuanto es inteligido, objeto contenido en una idea.

Aun al conocer algo particular hacemos un acto inmaterial ${ }^{10}$. ¿Qué es, en efecto, el ser espiritual o inmaterial sino "quod ei competit secundum quod habet esse in cognoscente"11.

La verdad es siempre un juicio, que el hombre realiza con la razón, acerca de la adecuación entre la cosa y el intelecto, el cual tiene la idea o inteligibilidad de la cosa. La verdad es una relación de adecuación o conformidad. Por esto, la identidad de la verdad (de la relación) no depende solo de la identidad de la cosa extramental, sino también de la identidad del intelecto ${ }^{12}$. Para que una verdad sea la misma verdad en los intelectos de los hombres diferentes, por ejemplo, se necesita, pues, que la cosa acerca de la cual tenemos verdad sea idéntica (no varíe para ninguno de los dos intelectos humanos) y es necesario, además, que los dos intelectos humanos, aún siendo numéricamente distintos, sean por sus formas idénticos y no solo semejantes.

Dijimos que la verdad es un juicio: una relación de adecuación entre la cosa y el intelecto. Cuando varía uno de los dos extremos, varía la verdad; pero no varía igualmente según varíe uno u otro extremo (esto es, la cosa o el intelecto). La verdad puede variar, a) por parte del intelecto, cuando (permaneciendo la cosa del mismo modo) tenemos de ella otra opinión; $b$ ) de parte de la cosa que cambia, permaneciendo la mente en la misma opinión. En estos dos casos la verdad varía cambiándose en falsedad ${ }^{13}$. Pero ahora no nos interesan estos dos tipos de cambio donde la verdad se pierde. Aquí nos queremos referir a cambios donde la verdad permanece siendo verdad, aunque diversa.

Pues bien, de más está decir que si un intelecto $-\mathrm{y}$ la verdad se da siempre en el intelecto - no padece cambio alguno, como es, según el tomismo, la mente divina, entonces en ella, que contempla todo desde toda la eternidad, la verdad es inmutable. La verdad, por el contrario, en el intelecto humano es mutable ${ }^{14}$. Si Sócrates está sentado, y así lo pensamos, tenemos un juicio verdadero, pues lo que pensamos concuerda con la

10 Cfr. S. Th., I, p. 79, a. 6 ad 2.

11 De Veritate, q. 18, a. 1, ad 3.

12 "Identitas veritatis non tantum dependet ex identitate rei, sed etiam ex identitate intellectus". De Veritate, q. 1, a. 6 ad 6.

13 Cfr. S. Th., I, q. 16, a. 8.

14 "Veritas divini intellectus est immutabilis. Varitas autem intellectus nostri mutabilis est", ibíd. 
realidad; pero si Sócrates se levanta permanece la verdad del pasado (es verdad, y lo será siempre que lo pensemos, que Sócrates estuvo sentado) mas no del presente referido a la cosa: en el presente tenemos otra verdad ("Sócrates se levanta").

Desde cierto punto de vista, podríamos decir que no es propiamente la verdad o relación de adecuación la que cambia, sino un extremo (la cosa) de esa relación que hace que tengamos otra opinión o idea de la cosa con la cual ahora debemos adecuar la cosa. En cierto sentido, la verdad "Sócrates se sienta" permanecerá siempre verdad como "Sócrates estuvo sentado".

Para que la verdad sea mudable, algo de la verdad deberá permanecer igual y algo debería cambiar. Mas esto no sucede, pues los dos términos de la relación cambian cuando cambia uno de ellos. Cuando Sócrates pasa de estar sentado a estar levantado, también la inteligibilidad o idea de estar sentado deja de aplicarse a Sócrates cuando está levantado. Más bien que decir que la verdad cambia, habría que decir, según esto, que adquirimos nuevas verdades.

Según esto, entonces, tiene sentido decir que la verdad de un intelecto sobre una cosa real es diversa de la verdad de otro intelecto sobre la misma cosa, si es diverso el modo y el medio de conocer de esos intelectos. Este es el sentido de una expresión muy repetida por Aquino: “Lo que se entiende, se entiende según el modo del que entiende" ${ }^{\prime 15}$ y esto no implica un relativismo.

El diverso modo de conocer (dados los diversos medios de conocer que poseamos: los ojos, un microscopio, un telescopio, etcétera) no cambia la realidad de las cosas conocidas; pero sí cambia la verdad (la ciencia o conocimiento cierto) que nos hacemos de las $\operatorname{cosas}^{16}$.

Las visiones ideológicas, con una única verdad absoluta (desprendidas del contexto y los medios de conocer) no es sino una prepotencia. Lo dicho debería hacernos docentes tolerantes de las diversas formas de conocer y estimularnos a dialogar acerca de lo que conocemos y de cómo lo conocemos, haciendo explícitos los intereses ocultos e ideologizadores. De hecho, el pensar y la verdad interesan cada vez menos y las personas se recuestan en la diversidad y la imagen.

Con un notable esfuerzo y coraje intelectual, Tomás de Aquino defendió que lo que se conoce se conoce al modo de cómo es quien lo conoce ${ }^{17}$. Pero actualmente se ha dado un paso más y peligroso: las cosas son como las siento.

\section{De la instrucción y educación a la seducción}

En buena parte, si bien el proceso de instrucción tiene por finalidad dar a los que aprenden herramientas para leer y escribir, y adquirir una cultura general,

\footnotetext{
15 “Cum omne quod intelligitur, intelligatur per modum intelligentis..." De Veritate, q. 15, a. 2; Cfr. De unitate intellectus contra Averroistas.

16 "Modus sciendi est in ipso sciente, non autem ipsa res scita secundum suam naturam est in ipso sciente; et ideo modi sciendi varietas facit scientiam variabilem, non autem variatio rerum scitarum”. De Veritate, q. 2, a. 13 , ad 8 .

17 "Modus cognoscendi rem aliquam est secundum conditionem cognoscentis, in quo forma recipitur secundum modum eius. Non autem oporret quod res cognita sit secundum modum cognoscentis”. De Veritate, q. 10 , a. 4.
} 
el proceso de educación es más que esto. La educación implica aprender a ser capaz de obtener el dominio de sí mismo, ser humanos libres y críticos (ser conscientes de los criterios que se están empleando), para no dejarse engañar y dominar mentalmente y, luego psicológica y físicamente, por causas alienantes.

Dicho brevemente, en la Posmodernidad, educar es intentar que Auschwitz no se repita; y puede repetirse, porque el mecanismo que lo hizo posible sigue existiendo y ha sido mejorado. La civilización moderna genera también la incivilización; la creciente capitalización lleva a la supresión de gran parte de lo humano de la humanidad. Será suficiente suprimir la ayuda a los países indigentes que generan emigraciones ingentes a los campos de refugio de los países vecinos, a veces tan pobres como ellos, pero en los que estiman podrán salvar sus vidas; a veces esperan llegar a los países del primer mundo; pero estos les cierran sus fronteras (después de haberles arrebatados las materias primas por siglos), y los devuelven a sus países de origen y levantan muros entre ellos.

¿Podrá repetirse un nuevo Holocausto? Bauman estaba preocupado por esta posibilidad que se dio en un país como Alemania, con una alta estima herida, con un gran sentido del deber, y capaz de cumplir órdenes sin protestar por lo ordenado.

Incidieron en este hecho, entre otras causas, la estrategia burocrática de impedir poner restricciones morales al egoísmo desenfrenado y al salvajismo latente en todos los hombres ${ }^{18}$. El Holocausto descubre el rostro oculto de la sociedad moderna, su colosal programa de ingeniería social, capaz de dar soluciones "racionales" a los "problemas" humanos.

Este programa de ingeniería hizo que el amor al prójimo desapareciera, pues a los judíos, gitanos y homosexuales, se los alejó: dejaron sistemáticamente de ser próximos y cada miembro de la organización no hizo más que cumplir, fraccionadamente, con su pequeño deber en el engranaje de la extinción de las personas. Ninguno de los miembros del sistema, cumpliendo con su deber, incumplió con las normas morales. La moral, en este caso, no ha sido externa a la responsabilidad de hacer bien el trabajo que a cada uno se le asignaba.

No pretendo decir - afirmaba Bauman - que la incidencia del Holocausto fue determinada por la burocracia moderna o la cultura de la racionalidad instrumental que ésta comprendía y, mucho menos, que la burocracia moderna produce necesariamente fenómenos parecidos al Holocausto. Lo que quiero decir es que las normas de la racionalidad instrumental están especialmente incapacitadas para evitar estos fenómenos, que no hay nada en estas normas que descalifique por incorrectos los métodos de "ingeniería social" del estilo de los del Holocausto o considere irracionales a las acciones que dieron lugar. ${ }^{19}$

18 Cfr. Zygmunt Bauman, Modernidad y Holocausto (Madrid: Sequitur, 2006), 25.

19 Ibíd., 39. 
Cuando se considera a la sociedad como un objeto a administrar fraccionadamente, se pierde el sentido de los medios, porque se ha perdido el sentido del fin de la sociedad. Y la finalidad de la sociedad no la da la tecnología social.

Los alemanes que fueron autores de los crímenes nazis no eran un tipo especial de alemán. Eran, en general, personas educadas; no eran "sudacas" o africanos primitivos. Pertenecían a una nación europea culta; pero las inhibiciones morales ante las atrocidades violentas disminuyen cuando se cumplen tres condiciones:

a) La violencia está autorizada, por órdenes oficiales emitidas por los departamentos legalmente competentes del Estado;

b) las acciones están dentro de la rutina burocráticamente delimitada en sus funciones: la disciplina (cumplimiento de la función atribuida y la negación de las opiniones personales) se convierte en la virtud fundamental para el funcionamiento del Estado ${ }^{20}$;

c) las víctimas de la violencia han sido previamente alejadas y luego deshumanizadas (convertidas en un número), como consecuencia de un proceso ideologizador.

Los organizadores del Holocausto tuvieron un notable éxito al no castigar públicamente a los judíos y a la vista de los vecinos. Con gran sentido ideológico de los eufemismos, las víctimas eran simplemente "deportadas" y luego eran llevadas a unas "duchas". En toda la cadena de mando y ejecución, cada uno personalmente no se veía enfrentado en forma consciente con las opciones morales de su conciencia: cada uno simplemente cumplía con su deber en un breve trayecto de una serie de la cual no veía ni el inicio ni el final. Entonces, el carácter moral de la acción o del valor final de la misma, permanece intencionalmente oculto. Cada uno es un instrumento inocente de una voluntad ajena. ¿Cómo puede suceder una gran maldad, cuando cada uno no ha hecho más que pequeñas cosas inofensivas, como recibir personas que son deportadas a otros lugares, como subirlas a un tren, como bajarlas del tren, etcétera?

La distancia física y psíquica de sus actos y efectos remotos hace que un prójimo ya no sea próximo; y que una persona poco a poco quede desposeída, desnacionalizada, desubicada, sin identificación y reducida a un número, debilitada, inutilizable, despersonalizada. Con esta tecnología, se ha logrado invisibilizar a la víctima.

El proceso socializador se vuelve ideológico (esto es, capaz de imponer su "verdad" a la fuerza) cuando queda libre del control social de los ciudadanos ${ }^{21}$. Entonces la violencia, racionalizada e institucionalizada en la política del Estado, queda libre de toda valoración moral ajena al partido. La racionalidad instrumental se atiene a la eficacia de la acción; pero se emancipa de la moral al emanciparse de las finalidades remotas de las acciones.

20 Cfr. Hannah Arendt, Eichmann en Jerusalén. Un estudio acerca de la banalidad del mal (Barcelona: Lumen, 2003), 83: “Tal como dijo (Eichmann) una y otra vez a la policía y al tribunal, él cumplía con su deber; no solo obedecía órdenes, sino que también obedecía la ley".

21 Cfr. José Simonetti, El ocaso de la virtud. Ensayos sobre la corrupción y el discurso del control social (Bs. As.: Universidad Nacional de Quilmes, 2018). 
El control social comienza a debilitarse cuando los socios que constituyen una sociedad comienzan a no desear involucrarse con la defensa de la constitución de la sociedad. Si bien la población alemana en general no despreciaba a los judíos (sobre todo a sus vecinos o próximos, bien conocidos), no obstante, tampoco deseaban involucrarse en su defensa. La ideología del Estado aprovechó esta situación para generar, primero, barrios o guetos apartados para judíos; para alejarlos luego "deportándolos", con la promesa de que iban a un lugar mejor; pero de modo que ya no fueran ni visibles ni próximos; para despersonalizarlos y finalmente exterminarlos.

Los mismos cristianos consideraron, en su liturgia hasta el tiempo del Concilio Vaticano II, a los judíos como "pérfidos judíos" que rechazaron y mataron a Cristo, como separados de la verdadera religión por no aceptar al Mesías, único poseedor de la verdadera palabra de Dios, cuando es verdad que ni siquiera el Sanedrín funcionó en la condena del rabino Jeshuá, sino que este fue entregado por el sacerdote Caifás y unos pocos, a los romanos y a duras penas condenado por Pilatos por revoltoso, pretendiente a ser rey de los judíos (INRI) según el gobierno romano.

El ser bárbaro o poder llegar a ser bárbaro, no es una cuestión de pasado. Si ser bárbaro consiste en no considerar la humanidad y libertad del otro, y esto ya ha pasado, podría volver a pasar22. No creamos ingenua o rousseaunianamente en la bondad natural del hombre o de nuestras creaciones burocráticas o de nuestra tecnología. La expulsión de los extranjeros en tiempos de crisis es frecuente.

Los seres humanos no son racionales, aunque por momentos pueden serlo; y aunque lo sean, la racionalidad necesita de sabiduría. Lo racional mira a los medios; la sabiduría se fija primeramente en los fines y solo luego en los medios. Son buenos solo los medios que realizan buenos fines. Un fin cualquiera no justifica cualquier medio. Pero aun en la búsqueda de nuestros fines podemos errar y dañar. El Holocausto es un indicador de que no podemos estar satisfechos con lo que hemos llegado a comprender acerca del ser humano.

Nada de lo que había sucedido hasta entonces había preparado a los pueblos cultos para comprender el Holocausto. Cuando sucedió, simplemente no lo podían creer.

De la globalización se puede retornar a la regionalización o nacionalización. El nacionalismo agresivo puede resurgir; una lectura fanática de la realidad social también puede revivir. El nazismo tiene nuevos adictos en Alemania y en EE. UU. En nombre de la Humanidad, se requiere un proceso de educación según el cual las personas no sean envueltas en un adoctrinamiento y fanatismo que lleve a repetir, en forma mejorada y seductora, el hecho de Auschwitz. Parecerá increíble, pero Alemania y Auschwitz también lo fue para muchos alemanes, en el pleno contexto de la Modernidad, un país del primer mundo, trabajador, obediente, responsable, con un personaje como Hitler que les prometió a los

22 Cfr. Tzvetan Todovov, El miedo a los bárbaros. Más allá del choque de civilizaciones (Barcelona: Galaxia Gutenberg - Círculo de Lectores, 2008), 33. 
alemanes recuperar su dignidad dañada con la primera guerra y expandir el territorio.

Hoy, el mismo deseo está presente, pero en forma camuflada mediante la seducción, donde todos pueden tener más placer, más visión en las pantallas, menos obligación de pensar y menos esfuerzo para poder comer: un mundo feliz. ¿Quién resistirá a esta oferta aparentemente gratuita? ¿Y no están en sus manos de los ideólogos infiltrar las adicciones globales? Ya no interesa dominar un territorio nacional en una época posmoderna donde las naciones han perdido poder: ahora importa el dominio global y casi imperceptible pero placentero, mediante la seducción, la que no genera una reacción violenta. Ya no hay una metrópolis y las colonias dominadas: ahora se da el expansionismo de un capitalismo avanzado y mundial, donde unos pocos - un $1 \%$ - tiene las riquezas y los medios de las que carece el $99 \%$. Y si es necesario cerrarán sus fronteras a los que antes saquearon.

No es suficiente la instrucción, la abundancia de conocimientos fáciles y a la mano. Se requiere educación, capacidad de discernir las influencias ideológicas, resistir a las frustraciones, y tener un sentido humano capaz de sacrificar algo de lo propio en favor de los inocentes esquilmados.

La seducción ha continuado y mejorado la técnica de adoctrinamiento, de la verdad única del proceso de capitalización para conducir a las personas. Ahora, las personas son conducidas y dominadas, mediante la seducción, suprimiéndoseles la objetividad y libertad de una forma placentera y masiva. Seducida la persona puede terminar, por una parte siendo adicta y, por otra, defendiendo su adicción esclavizante, sin reconocer o importarle la pérdida de su libertad. ¿Qué puede importarle a un pobre la libertad, si libre, no tiene para comer?

Siempre se ha dado en Occidente un recelo entre la dialéctica, la retórica y la lógica.

La lógica y la dialéctica requieren razonamientos y mover formal y fundadamente las mentes humanas. La retórica apela a la seducción, a atraer y subyugar al contrincante, sin quitarle la sensación de que es él el que decide en su vida, ante un abanico prolífero de ofertas a consumir.

La sociedad de consumo utiliza la lógica de la seducción, haciendo que el seducido se sienta importante, como si él se eligiese y condujese con plena libertad (se-ducere: conducirse a sí mismo) ofreciéndole cada vez más opciones y combinaciones a su medida. La adicción al celular o teléfono móvil es un claro ejemplo, que los adictos difícilmente querrán admitir: se sienten libres y mimados por su utilidad, hasta el punto que los usuarios entran en pánico si no lo tienen constantemente en sus manos, reduciendo obsesivamente la mayor parte de sus horas a oír música y ver mensajes o fotos en sus celulares. Esta forma ideológica en que el mercado de capitales conduce a las masas se ha naturalizado. Los niños, aún con pañales, se habitúan al teléfono celular antes de saber leer y escribir: el mundo posmoderno comienza a entrar y a reducirse a una ventana o pantalla.

La cultura de la seducción tiene, sin embargo, elementos positivos y rescatables: deja las relaciones autoritarias y dirigistas, y privilegia la pluralidad 
y diversidad de opciones; pero también impele a la realización de los deseos desoyendo los llamados a la austeridad; genera ocultamente una jerarquía, pero potente de valores, donde se privilegia el consumo irracional, la imagen sobre el pensamiento. Nuestros ídolos son ahora los que poseen y se muestran en las pantallas. Si en la Modernidad lo importante era: "Pienso luego soy", actualmente, en la Posmodernidad lo importante es "Estoy en una pantalla, luego existo".

Mientras se esté en el ámbito del consumo, no importan luego las formas, porque el seducido es finalmente un cliente cautivo por el monopolio de la seducción, a la que condesciende creyéndose protagonista ${ }^{23}$.

Indudablemente, pareciera que los países del tercer mundo y los hombres del trabajo serían los más reacios a asumir la lógica de la seducción. Mas nuestra sociedad global va teniendo siempre más jóvenes, y más numerosos, seducidos por el espejismo del consumo. Estos requieren diversión, o al menos contención, y privilegian la comunicación a la coerción. El pobre desea parecerse al menos en algo al rico teniendo un buen celular y quién se lo podrá negar en el contexto de que el poseer es igual a ser.

Las personas jóvenes, adolescentes hasta los treinta años, libres en sus tiempos, con creciente autonomía y cuidado del cuerpo, generan la exigencia de una educación que cubra esos deseos: permisividad, homeostasis de los feelings, socialización suave, plural y diversa ${ }^{24}$.

La cultura posmoderna de la seducción se acompaña de ritmo, rápido, vociferado, constante, sin contenido, por lo que no importa en qué lengua se cante o se grite sin comprenderlo.

La revolución musical y la tecnología sacan al oyente de su mundo manteniéndolo en suspenso, sin transportarlo a otro lugar o a otras ideas. El individuo se vuelve cinético y desea sentir más. La velocidad fascina y hace sentir la vida en la piel. Los jóvenes pueden pasar muchas horas charlando, pero luego, cuando suben a un vehículo, quieren velocidad.

Se da una nueva forma de control social por medio de la seducción. La seducción es soft, distrae epidérmicamente a un público que, sin embargo, no es ingenuo ni pasivo.

La seducción no funciona con el misterio, sino con la información, con la propuesta de la supresión de las relaciones burocráticas del poder.

La seducción suprime la revolución y el uso de la fuerza, y opera por relación, cohesión y acercamiento, dando la sensación de que es cada uno el que decide.

Verlo todo, hacerlo todo, decirlo todo porque no puedo parar de hacerlo, define a la seducción ${ }^{25}$.

La seducción lucha contra la inmovilidad y busca el autoservicio libidinal. El cuerpo y el sexo se vuelven instrumentos de subjetivación. Los jóvenes posmodernos marcan sus cuerpos para indicar que son únicos.

23 Cfr. Z. Bauman, Mundo consumo. Etica del individuo en la aldea global (Buenos Aires: Paidós, 2010).

24 Cfr. Gilles Lipovetsky, Educar en la ciudadanía (Valencia: Institución Alfonso el Magnánimo, 2016).

25 Gilles Lipovetsky, La era del vacío. Ensayos sobre el individualismo contemporáneo (Barcelona: Anagrama, 2004), 29. 
Se da integridad al cuerpo antes que ocultarlo. El cuerpo se convierte en persona a respetar. El cuerpo es directo: se expresa, seduce moviéndose bajo el hechizo de la sonorización estridente.

La seducción es, en parte, sexducción, adaptando a la mujer al rango de las sociedades democráticas hedonistas. Pero esto no da lugar a Don Juan, sino a Narciso "subyugado por sí mismo en su cápsula de cristal" 26.

La cultura de la seducción viene estimulada por la indiferencia, entendida como clima cultural.

\section{El narcisismo y selfish: esclavos de la propia imagen y apatía}

En la época moderna, los problemas de la política (de cómo queremos vivir socialmente) movía a los jóvenes, uniéndose, por ejemplo, los universitarios y los obreros (París, mayo de 1969); y siendo capaces de cambiar los gobiernos.

En la Posmodernidad, el poder político se ha psicologizado: de la esfera social ha pasado a la esfera psicológica. Ya casi no se rediscuten ideas y programas políticos, lo que lleva a veces a una perversión de las democracias y manipulación del electorado con el espectáculo de las ilusiones. La imagen manda, se impone, y el tiempo televisivo es tiránico: no permite la discusión si no hay venta en el programa.

El marketing político es programado y cínico. La seducción juega a la descentralización; y el Estado, mientras se descomprime, deja la iniciativa a los consejeros locales o regionales. Deja las instancias de decisión a los individuos, mientras los sigue manejando con la administración del control económico y los impuestos recaudados.

El sexo se hace político y no pocas veces se traduce en un medio para lograr relaciones de poder. A través del aborto libre y gratuito se apunta al derecho de la autonomía y responsabilidad ante la procreación. En nombre de esa autonomía, se condenan los celos y la posesividad. Las relaciones quedan flotando, sin compromiso profundo hasta llegar, frecuentemente, a un estado de indiferencia como venganza preventiva ante la posible frustración de las altas exigencias que cada uno imagina o desea del otro. Una cuarta parte de los compradores de viviendas, en los países económicamente fuertes, son para personas que desean vivir solas. Es una forma de protegerse de los propios impulsos y de las decepciones; un búnker para la indiferencia. No se trata de deshumanización, sino de una personalización sin sentimientos rituales y ostentosos. Por ello, aun desde este búnker hay tiempo para salir a clubes de encuentros, recurrir a los pequeños anuncios, las redes virtuales y chateos. No se abandona la esperanza en el milagro de la intensidad emocional, que resulta ser cada vez más difícil y breve: en realidad se da menos sexo vivido que antes.

La única relación peligrosa de pareja parece ser la prolongada indefinidamente, monótona, rutinaria.

26 Ibíd., 339. 
Bajo el imperativo de la transparencia, aparecen las campañas contra la violación y el acoso.

Las parejas desean vivir sin niños. La vida se precariza en existencias individuales regidas solo por sí mismas. La indiferencia no es el resultado de la inconsciencia, sino de una nueva conciencia dolida. Nunca tenemos tiempo suficiente para preocuparnos por las necesidades de alguien más; siempre nos preocupamos por nuestras necesidades y nos convertimos en adictos emocionales y virtuales.

Cuando lo social está abandonado, el deseo, el placer, la comunicación, se convierten en los únicos "valores", y los psicólogos son los grandes predicadores del desierto. Es la realización extrema del capitalismo, en su lógica fundamental.

"La apatía no es un defecto de socialización sino una nueva socialización flexible y 'económica'”27.

La indiferencia metapolítica, metaeconómica, permite que el capitalismo funcione.

Cuanto más los políticos se explican o exhiben en la tele, más la gente se ríe. Cuanto más quieren los profesores que los estudiantes lean, menos leen y ven imágenes. Es una indiferencia por saturación, por información y aislamiento.

No se es indiferente por falta de motivación, sino porque el individuo no se aferra a nada, no tiene certezas absolutas. Nada lo sorprende y puede cambiar rápidamente de opinión. Para movilizar se requiere mucha imaginación e información. Si hasta la Edad Media lo importante era llegar a la verdad (única, eterna), hoy lo que importa es la diversidad a la carta sin drama en el cóctel de la indiferencia.

La democracia ha creado una erosión de las formas de alteridad clásicas, y marca un impulso a la igualdad de las condiciones: desubstanciación de las categorías sociales y procesos de personalización a la carta, desmontando todas las diferencias antes consideradas esenciales: no importa el sexo (masculino o femenino), sino el género (lo que tú te sientes).

Cada ciudadano busca la autenticidad, sin un yo y sin un otro definido.

Nunca como hoy la democracia ha funcionado sin un enemigo interno declarado. Los individuos están preparados para tener que elegir; son alérgicos al autoritarismo y a la violencia. Desean cambios permanentes pero sin riesgos considerables. A medida que crece en narcisismo, crece la legitimidad democrática que sostiene la demanda de libertad, de elección, de pluralidad y pluralismos de partidos, aunque disminuya la militancia partidaria, y la política tome un tono de espectáculo.

Hay indiferencia, pero ello no afecta al respeto por la democracia: los jóvenes posmodernos no leen los periódicos, pero exigen libertad de expresión.

El deseo de igualdad sigue vigente, pero con medios más flexibles y menos violentos. Se estima que la ineficacia burocrática es la causante de la lentitud del proceso hacia la igualdad. Mas la demanda de libertad es superior al de la

27 Ibíd., 43. 
igualdad, lo que lleva implícitamente a una preferencia por el liberalismo antes que por el socialismo.

De la democracia, los ciudadanos esperan hoy, ante la individuación, seguridad y programas de protección. Se da un resentimiento contra los Estados nacionales, acusados de ser incapaces de asegurar las funciones positivas como la de la justicia y la salud; frenar la inseguridad generada por la criminalidad y la marginación social ${ }^{28}$. El malestar en la cultura política posmoderna es multivariado.

Los ideales de bienestar, la pérdida de crédito de los grandes sistemas, las extensiones de los deseos y derechos a la autonomía subjetiva han vaciado de su sustancia a los deberes cívicos al igual que han desvalorizado los imperativos categóricos de la moral individual e interindividual; en el lugar del civismo, tenemos el culto de la esfera privada y la indiferencia hacia la cosa pública, el "dinero todopoderoso" y la "democratización" de la corrupción. ${ }^{29}$

El hombre democrático no es, sin embargo, un hombre mediocre. Hay grandes sectores de investigadores, empresarios, deportistas, deseosos de aprender, de mejorar, de vencer, y la democracia posibilita lograrlo. Unos se obsesionan con el bienestar, otros con el progresar y superarse. El deseo por vivir no está en peligro, no obstante la indiferencia en la que se vive.

El capitalismo autoritario cede el camino al capitalismo hedonista y permisivo.

La Modernidad era espíritu de empresa, esperanza futurista; hoy instala la última versión del hombre igual: el narcisismo. La protesta estudiantil ha desaparecido.

El narcisismo es el movimiento de repliegue personal o social y grupal si hablamos de narcisismo como forma de vida socializada. El narcisismo es el movimiento de repliegue por el cual el sujeto retira su libido objetal y la aplica a sí mismo como sujeto singular o socializado (grupal, cultural). Toda la fuerza vital del sujeto se concentra en su interior con el fin de salvaguardarse. El narcisismo es un movimiento regresivo que hace abandonar el estadio de las relaciones objetales para volver al estadio primero del amor exclusivo de sí mismo. Algunas frustraciones son inevitables en la existencia humana y necesarias para la maduración del yo y, si son soportadas, serán frustraciones normales; si impiden la realización del yo en la interacción con su mundo, impedirán la maduración del yo y se volverán patológicas. Las frustraciones que, por su intensidad o por su acumulación, exceden las posibilidades de adaptación del sujeto individual o social, hacen que el sujeto se retrotraiga del mundo que lo frustra y lo hace sufrir.

28 G. Lipovetsky, El crepúsculo del deber. La ética indolora de los nuevos tiempos democráticos (Barcelona: Anagrama, 2006), 201.

29 Ibíd., 203. 


\section{CONCLUSIÓN}

\section{Concluyendo perdidos en la banalización social}

El narcisismo es el resultado de lo que una persona o una sociedad estima como privación de amor. Cuando un bebé (o una sociedad) llora y nadie lo atiende, deja de llorar y se vuelve indiferente, inexpresivo e independiente, generalmente solitario, triste y agresivo. La persona feliz, no frustrada, manifiesta buen humor, euforia, expande vida, ama a los demás. Los grados de narcisismo dependen siempre de la frustración en función de la subjetividad del que la sufre, sea una persona singular o una sociedad (una cultura).

El narcisismo se manifiesta en dos órdenes de signos: a) como ruptura más o menos completa de las relaciones afectivas con el mundo circundante; y b) en la estimación de los demás, con una supervaloración del sujeto. Éste estima que no es justamente amado por los demás y genera una actitud de desvalorización de los demás ${ }^{30}$.

Se da una banalización social, una presente ausencia en el escenario de los otros: o bien, por un lado, vivir sin ideales, sin objetivos trascendentes, dejarse llevar, vivir el presente, sin sentimiento de pertenencia, sin sentido histórico o bien, por otro lado, vivir en la soledad psicológica y retraída del que se estima héroe injustamente ignorado.

Se implementan estrategias narcisistas de supervivencia: salud psíquica y psicológica. Retirarse en el presente, reciclando la juventud.

La ausencia de grandes ideales a los que nos tenía acostumbrado la Modernidad, se presenta como un nihilismo, que es vivido sin tragedia, si no con apatía frívola, sin sentimiento trágico por el fin del mundo, con apatía epidérmica e indiferencia hacia el mundo. No hay Quijotes que salgan a salvar al mundo. Incluso la amenaza de calentamiento global no es suficiente para organizar una cruzada, aunque el papa Francisco la quiera lanzar con su encíclica Laudato si'. La juventud (una categoría que está en crecimiento dada la explosión demográfica) no lee los diarios, ni se informa de las noticias: si puede, se divierte de noche y duerme de día.

Ante la deserción de los valores sociales, se acentúa la personalización como hiperinvención del yo y abandono de los grandes sistemas de sentido (ideales políticos, religiosos y culturales). Se vive en el vacío.

El narcisista estima que amarse a sí mismo es suficiente, de modo que no se necesita de otro para ser feliz...

Los individuos se esfuerzan por liberarse de los sistemas de defensa anónimos, que cortan la continuidad histórica de los sujetos. Para la liberación buscan asociaciones "libres", el grito, el sentimiento animal, lo no verbal. El analista no es un referente y, en el narcisismo total, cada uno queda en manos de sí mismo, regido por la autoseducción del deseo.

30 Cfr. Louis Corman, Narcisismo y frustración de amor (Barcelona: Herder, 2014), caps. II y III. 
La autoabsorción permite el abandono de la esfera pública. Las religiones tratan de aprovecharse de la coreografía, de la música actual y de mensajes masivos para poder sobrevivir y reclutar adeptos. De la religión del libro se exige pasar a la religión del espectáculo, so pena de indiferencia por el contenido.

El yo se convierte en un espejo vacío a fuerza de flashes de 'informaciones' ${ }^{31}$, sin análisis, ni ubicación en el contexto histórico. Importa poco saber si Napoleón vivió antes o después de Jesucristo.

El narcisismo neutraliza el universo social, vaciando las instituciones de sus inversiones emocionales y el yo se vacía de su identidad, por eso requiere constantemente de las selfish para reírse de sí mismo.

El yo pierde su referencia de unidad por exceso de información insustantiva.

A los escritores no les queda otro recurso que el novelesco breve, donde cada uno puede moverse al ritmo de su propia fantasía.

El esfuerzo y los deberes no están de moda. Lo que supone sujeción o disciplina austera se ha desvalorizado y se busca lo placentero de realización inmediata.

La anarquía de los impulsos, la pérdida de un centro de gravedad otorgado por ideales, genera una voluntad débil, no intra-determinada.

El posmoderno se mueve en el clima de la no-directividad, de la asociación libre, de la espontaneidad creativa, de la cultura de la expresión, de la dispersión en detrimento de la concentración, de la aniquilación de las síntesis conceptuales.

Parece generalizarse la falta de atención de los alumnos, concertada, persistente y esforzada (queja de todos los profesores), a favor de una atención dispersa. Se hace presente una conciencia telespectadora, que parece captarlo todo y nada; excitada e indiferente a la vez.

El yo se disuelve en tendencias parciales, moléculas personalizadas, nuevos zombis atravesados por mensajes de textos, sin ortografía ni sintaxis: simplemente palabras yuxtapuestas y emoticones.

El yo narcisista es lábil, sometido sistemáticamente a experimentación rápida.

El narcisismo es un sistema flotante, que produce la última personalidad de masa, apta para sistemas de consumo.

No hay comportamiento orientado por un modelo y por su aprobación, lo que daba sentido a la acción social. Por el contrario, se produce la licuación de la identidad rígida del yo. Va desapareciendo el amor por la patria (sustituido por el amor pasajero al paisaje). No se ocultan las debilidades de los héroes.

El narcisismo no es una falta de personalidad, sino una nueva personalidad con una conciencia indeterminada y fluctuante, sin saber qué hacer, acorralada constantemente por el aburrimiento.

Se intentan elaborados comportamientos de ortopedistas de la salud física y mental: se impone la formación permanente, al menos como lifting que levanten las partes caídas del cuerpo y levanten el humor.

31 Cfr. Lipovetsky, La era del vacío, 56. 
Se flexibilizan las categorías sociales acerca de quién es mujer, hombre, niño, civilizado, loco, etcétera: la indefinición e incertidumbre se expanden.

El posmoderno narcisista teme envejecer y morir. La vejez se vuelve una idea intolerable. Se trata de que el dolor deje de ser real.

La frialdad y el anonimato parecen vicios inaceptables: las virtudes se dirigen hacia el revelar las propias motivaciones, las intimidades, todo lo cual es índice de autenticidad y sinceridad. No importa la verdad (que pretende ser objetiva), pero sí la sinceridad: exponer frívolamente las intimidades y culebrones en la televisión, Twitter o Facebook, etcétera ${ }^{32}$.

El desencantamiento y el vaciamiento de convicciones y valores religiosos han conducido también al estrechamiento y a la banalización de la esfera íntima, concediendo un valor prioritario a aspectos más relacionados con la esfera privada, como la estética, el consumo y las aficiones personales ${ }^{33}$.

Quedan, sin embargo, esperanzas: estas se hallan en el proceso educativo, no solo en el aspecto intelectual, sino sobre todo en la formación de una forma de vida compartida, cooperativa y responsable.

\section{REFERENCIAS}

Álvarez Ramos, Eva, Hugo Heredia y Manuel Romero. “La Generación Z y las Redes Sociales. Una visión desde los adolescentes en España". Revista Espacios 40, n. 20 (2019).

Aray, María del Carmen. "El miedo asecha y el consumo seduce. Dos caras del modelo psicológico dominante en tiempos de globalización". Universitas Humanística n.ํำ 67 (2009): 55-80.

Arendt, Hannah. Eichmann en Jerusalén. Un estudio acerca de la banalidad del mal. Barcelona: Lumen, 2003.

Ariño Villarroya, Antonio. “Ideologías, discursos y dominación”. Reis. Revista Española de Investigaciones Sociológicas n.․ 79 (1997): 197-219.

Bauman, Zygmunt. Vida de consumo. Buenos Aires: Fondo de Cultura Económica, 2009.

Bauman, Zygmunt. Vida líquida. Buenos Aires: Paidós, 2009.

Bauman, Zygmunt. Modernidad líquida. Buenos Aires: Fondo de Cultura Económica, 2009.

Bauman, Zygmunt. Mundo consumo. Ética del individuo en la aldea global. Buenos Aires: Paidós, 2010.

Bauman, Zygmunt. Tiempos líquidos. Vivir en una época de incertidumbre. Buenos Aires: Tusquets, 2009.

Daros, William R. Epistemología y didáctica. Rosario: Mathesis, 1984.

Daros, William R. "Diversidad de la verdad y relativismo en el pensamiento de Tomás de Aquino". Conferencia pronunciada en Estratto da Atti dell'VIII Congresso Tomistico Internazionale, Napoli, vol. V, 1982.

García, José Ramón. “Teoría crítica en Ciencias Sociales: Conocimiento, racionalidad e ideología”. Revista de Ciencias Sociales n. 80 (1998): 61-76.

Gómez, Ricardo J. Neoliberalismo y seudociencia. Buenos Aires: Lugar Editorial, 2005.

Corman, Louis. Narcisismo y frustración de amor. Barcelona: Herder, 2014.

Ianni, Octavio. La sociedad global. México: Siglo XXI, 2008.

Lipovetsky, Gilles. Educar en la ciudadanía. Valencia: Institución Alfonso el Magnánimo, 2016.

32 Cfr. Eva Álvarez Ramos, Hugo Heredia y Manuel Romero, "La Generación Z y las Redes Sociales. Una visión desde los adolescentes en España", Revista Espacios vol. 40, n. ${ }^{\circ} 20$ (2019).

33 Cfr. Carmen Sabater Fernández, "La vida privada en la sociedad digital. La exposición pública de los jóvenes en Internet", Aposta. Revista de Ciencias Sociales n. ${ }^{\circ} 61$ (2014). http://www.apostadigital.com/revistav3/hemeroteca/csabater.pdf 
Lipovetsky, Gilles. El crepúsculo del deber. La ética indolora de los nuevos tiempos democráticos. Barcelona: Anagrama, 2006.

Lipovetsky, Gilles. La era del vacío. Ensayos sobre el individualismo contemporáneo. Barcelona: Anagrama, 2004.

Luna Reyes, Ambrosio Javier. "Ilusión, seducción, persuasión". Tópicos del Seminario n. 14 (2005): 87-109.

Ojeda Figueroa, César. La presencia de lo ausente. Ensayo sobre el deseo. Santiago de Chile: Cuatro Vientos Editorial, 2018.

Quiroga, Hugo, Susana Villavicencio y Patrice Vermeren, compiladores. Filosofías de la ciudadanía. Sujeto político y democracia. Rosario: Homo Sapiens Ediciones, 1999.

Reboul, Olivier. L'endoctrinement. París: PUF, 2007.

Sabater Fernández, Carmen. "La vida privada en la sociedad digital. La exposición pública de los jóvenes en Internet". Aposta. Revista de Ciencias Sociales no 61 (2014). http://www. apostadigital.com/revistav3/hemeroteca/csabater.pdf

Santo Tomás de Aquino, Suma de Teología. Madrid: Biblioteca de Autores Cristianos, 1998.

Simonetti, José. El ocaso de la virtud. Ensayos sobre la corrupción y el discurso del control social. Buenos Aires: Universidad Nacional de Quilmes, 2018.

Todovov, Tzvetan. El miedo a los bárbaros. Más allá del choque de civilizaciones. Barcelona: Galaxia Gutenberg - Círculo de Lectores, 2008.

Van Dijk, Teun. Ideología. Una aproximación multidisciplinaria. Barcelona: Gedisa, 2014.

Zizek, Slavoj. El sublime objeto de la ideología. México: Siglo XXI, 2012.

Cómo citar:

Roberto Darós, William. "Seducir o adoctrinar. La educación ante las formas moderna y posmoderna de la esclavitud" Revista Historia de la Educación Latinoamericana. vol. 22 No. 34 (2020): 73-94

DOI: https://doi.org/10.19053/01227238.11352

() $(\mathcal{Q} \Theta \Theta$ Esta obra está bajo una licencia Creative Commons. Reconocimiento-No Comercial-Sin Obra Derivada 2.5 Colombia. 